\title{
AVALIAÇÃO DO SISTEMA DE GERENCIAMENTO DE ÓLEOS LUBRIFICANTES USADOS OU CONTAMINADOS NO
} BRASIL

\author{
Malaquias Zildo António Tsambe ${ }^{*^{*}}$, Cássio Florisbal de Almeida ${ }^{1}$, Gabriele Lohmann ${ }^{1}$, Mariana Ribeiro Santiago ${ }^{1}$, Luiz Fernado \\ de Abreu Cybis ${ }^{2}$ \\ ${ }_{1} P P G$ em Recursos Hídricos e Saneamento Ambiental, UFRGS - IPH, 91501-970, Porto Alegre, Brasil. \\ 2 Professor do departamento de Obras Hidráulicas, UFRGS - IPH, 91501-970, Porto Alegre, Brasil.
}

*E-mail: m.tsambe@yahoo.com.br

\section{RESUMO}

A crescente conscientização em relação ao desenvolvimento tecnológico que atenda as questões relacionadas à sustentabilidade constitui um marco importante para a garantia da satisfação socioeconômica e ambiental. A Política Nacional de Resíduos Sólidos (PNRS) e a resolução 362/2005 do Conselho Nacional de Meio Ambiente (CONAMA) são alguns dos instrumentos legais que garantem a materialização parcial dessa conscientização. O presente estudo avalia o estágio atual do sistema de gerenciamento do Óleo Lubrificante Usado ou Contaminado (OLUC), discute a legislação vigente para o setor e as tecnologias usadas para o seu reaproveitamento. O gerenciamento adequado do OLUC é fundamental para evitar o conjunto de problemas ambientais resultantes do seu descarte inadequado, como a contaminação da água, do solo e do ar. Atualmente, o Brasil é o sexto maior consumidor mundial de óleos lubrificantes, consequentemente, o sexto maior produtor de OLUC, com uma produção de cerca de um milhão de litros/ano. O País atingiu a capacidade de coleta de 38,5\%, considerada satisfatória de acordo com a meta de coleta mínima estabelecida pela UNEP e pela resolução 362/2005 do CONAMA. Os resultados sustentam a necessidade de melhorar o gerenciamento do OLUC, desde as questões socioeconômicas às ambientais. Existe a necessidade urgente de fiscalizar e monitorar a atividade a fim de minimizar os impactos causados pela destinação inadequada de OLUC.

Palavras-chave: OLUC. Gerenciamento. Rerrefino.

\section{Introdução}

As crescentes atividades industriais formam o cenário que impulsiona a indústria de Lubrificantes em todo o mundo, particularmente do setor automotivo, que registrou um crescimento mundial médio anual de cerca de 5\%, entre 2000 a 2009, sendo a América do Sul (Brasil - 7,59\%) e a Ásia (China - 24,2\% e Índia - $14,56 \%$ ) as regiões com maior crescimento [1]. Este cenário impulsionou a indústria de Lubrificantes em todo o mundo. Os meios de transporte, os diversos e mais variados equipamentos motorizados têm algo em comum, a necessidade de lubrificantes para seu perfeito funcionamento. A consequência imediata do uso de lubrificantes é a grande quantidade de Óleo Lubrificante Usado ou Contaminado (OLUC) gerada durante a fase de manutenção dos equipamentos motorizados colocados à disposição da sociedade $[2-3]$.

O óleo lubrificante é utilizado em equipamentos motorizados para reduzir o atrito entre as superfícies em movimento e que, com o tempo, desgastam-se pela contaminação por metais de desgaste do motor, água de combustão, entre outros químicos produzindo o OLUC. Quando a quantidade de contaminantes é excessiva, o lubrificante perde suas características físico-químicas e deve ser substituído. Nessa fase, os lubrificantes adquirem o estágio de OLUC [4-5]. Em muitos casos, o OLUC carece de um sistema de gestão (coleta e posterior tratamento) específico. Em vários centros urbanos, o OLUC é lançado diretamente ao ambiente (em meio hídrico, pelas redes de esgotos e no solo) e por vezes, queimado de forma não controlada [2,5].

O gerenciamento informal do OLUC é caracterizado por sua destinação inadequada, como são os casos da sua utilização informal como combustível em processos térmicos e descarte em aterros clandestinos [6]. Essas ações constituem um risco, pois o OLUC é caracterizado por apresentar na sua composição química substâncias que perigam tanto a saúde humana quanto ao meio ambiente. Uma vez lançado ao ambiente, o OLUC provoca impactos negativos sobre a vida animal e vegetal. $\mathrm{Na}$ água, forma uma película de óleo sobre a superfície e impede a entrada de luz solar e de oxigênio, 
necessários para o ecossistema aquático; quando depositados no solo, diminuem a sua capacidade de filtração e troca iônica, bem como a fertilidade do solo; e quando queimados liberam gases tóxicos ao meio ambiente [2-3,7].

A logística reversa do OLUC e de outros resíduos resultante dessa atividade deve contemplar a sua geração, substituição e atribuição de um destino ambientalmente adequado, a fim de evitar a contaminação do meio ambiente. Isto é especialmente importante em termos de responsabilidade coorporativa, não apenas para as empresas geradoras do OLUC, mas também para as indústrias de rerrefino e a comunidade $[2,8]$. Para isso, a resolução $n^{0} 362 / 05$ do CONAMA prevê a coleta e posterior rerrefino deste resíduo classificado, pela NBR 10.004, como um resíduo perigoso, pois representa risco de contaminação ambiental. O gerenciamento ambientalmente correto do OLUC torna-se um desafio à sociedade em relação à necessidade de minimizar os riscos que podem ocorrer por causa do seu descarte incorreta. Assim, a gestão sustentável deste resíduo não deve ser limitada aos aspectos ambientais, mas conjugada aos aspectos sociais e econômicos no sentido de agregar todos os componentes que tornariam a sua abordagem efetivamente sustentável [8].

O ciclo de vida do OLUC é constituído fundamentalmente pelos diversos atores da cadeia de geração, coleta e reciclagem desse resíduo, que são responsáveis pela sua conversão em um novo óleo lubrificante. Esse conjunto de atividade é cada vez mais reconhecido como um elemento essencial de boa gestão ambiental por parte dos intervenientes da cadeia. Portanto, é importante que cada interveniente nomeadamente, geradores de OLUC, transportadores, coletores e rerrefinadores compreendam as questões de responsabilidade compartilhada no gerenciamento desse resíduo perigoso [5-6,89].

Este estudo tem como finalidade apresentar o estágio atual do gerenciamento do OLUC durante seu ciclo de vida, isto é, a sua geração, coleta, rerrefino ou outro destino ambientalmente seguro.

\section{2 Óleos Lubrificantes}

No período de 2000 a 2011 a demanda mundial de óleos lubrificantes foi de cerca de 36 milhões de toneladas por ano, como mostra a figura 1. A região da Ásia-Pacífico deteve o maior mercado mundial de consumo médio anual, cerca de $41 \%$, sendo os Estados Unidos da América (EUA) a segunda maior região com um consumo médio anual de cerca de $20 \%$. Em 2012, foram consumidos cerca de 45 bilhões de litros de óleo lubrificante no mundo, gerando, como resíduo, cerca de 30 bilhões de litros de OLUC. A National Oil Recycles Association (NRO) estima que nos EUA cerca de mais de 758 milhões de litros de OLUC são ilegalmente gerenciados, não sendo gerados e consequentemente coletados para a destinação legalmente estabelecida. Esta quantidade de OLUC é descartada ilegalmente e/ou acidentalmente em esgotos, córregos, fossos e aterros, e representa cerca de $40 \%$ da poluição por derivados do petróleo, isso torna urgente a adoção de políticas que melhorem o gerenciamento do OLUC [2,9-10].

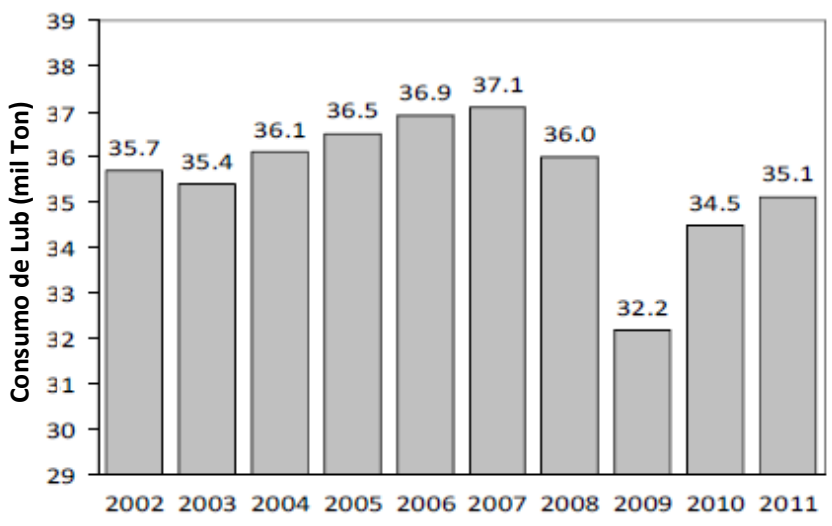

Ano

Figura 1: Consumo mundial de óleo lubrificante entre 2002 a 2011. Fonte: $[2,9]$

Em 2014, o Brasil tornou-se o sexto maior consumidor de óleos lubrificantes e, consequentemente, o sexto maior produtor de OLUC, responsabilizando-se pelo consumo de aproximadamente 15 milhões de litros de óleo lubrificante por ano [11].

\section{1 Óleos lubrificantes acabados}

São substâncias elaboradas para cumprir a função principal de reduzir o atrito entre superfícies móveis em um objeto [2]. Dependendo da sua aplicação, também podem servir para propósitos secundários, sendo comum o uso como agentes refrigeradores na remoção e transferência de calor, de limpeza das partes móveis, como vedantes, isolantes e como protetor de componentes contra corrosão e oxidação [5]. Os óleos lubrificantes, sintéticos ou não, são derivados diretos ou não do petróleo, apresentam alta viscosidade e longas cadeias de hidrocarbonetos alifáticos e aromáticos empregados para fins automotivos, industriais ou outros. Após o período de uso recomendado pelos fabricantes dos equipamentos e do óleo, deteriora-se parcialmente, formando compostos oxigenados (ácidos orgânicos e cetonas), compostos aromáticos polinucleares de viscosidade elevada (potencialmente carcinogênicos), resinas, lacas e outros contaminantes [12].

Uma grande percentagem em massa dos óleos lubrificantes, cerca de $80-90 \%$ é originada a partir do óleo básico (variando em razão do tipo do óleo lubrificante a produzir) ao qual são adicionados $5-20 \%$ de aditivos (anticorrosivos, antioxidantes, dispersantes, detergentes, melhoradores do índice de viscosidade etc.) capazes de proporcionar as características necessárias às suas diversas aplicações (industriais ou automotivas) [5]. Em função da fonte 
ou processo de obtenção, o óleo base pode ser classificado em: i) mineral - obtido através da destilação e do refino do petróleo (dependendo do tipo de hidrocarboneto predominante podem ser classificados em parafínicos ou naftênicos); ii) sintético produzidos a partir de reações químicas e a partir de produtos geralmente extraídos do petróleo e; iii) composto ou semissintético - obtido da mistura de dois ou mais tipos diferentes de óleo base $[5,13]$.

O óleo lubrificante acabado é o produto da mistura do óleo básico (mineral, sintético ou semissintético) com aditivos (anticorrosivos, antioxidantes, dispersantes, detergentes, melhoradores de índice de viscosidade, entre outros), que servem fundamentalmente para conferir determinadas características necessárias às diversas aplicações (em equipamentos industriais, em automóveis ou para outro fim) do óleo lubrificante. É importante salientar que os óleos lubrificantes a base de óleo mineral são considerados uma matéria prima nobre, pois correspondem a uma pequena fração do petróleo. Cerca de $2 \%$ dos derivados do petróleo constituem o óleo lubrificante e estes constituem a fração que não é totalmente consumida durante o seu uso [13].

\section{2 Óleo lubrificante usado ou contaminado}

O óleo lubrificante usado ou contaminado (OLUC) é produto da degradação do óleo lubrificante, contaminado ou deteriorado durante o seu uso em motores a combustão, sistemas de transmissão e sistemas hidráulicos [5]. Ele é caraterizado por conter produtos resultantes da deterioração parcial do lubrificante, tais como compostos oxigenados, polinucleares aromáticos de viscosidade elevada (PNAs), resinas e lacas. Além dos produtos de degradação, estão presentes no OLUC os aditivos (fenóis, compostos de zinco, cloro, enxofre ou fósforo) adicionados ao óleo básico no processo de formulação do óleo lubrificante e que não tenham sido consumidos, tais como metais de desgaste dos motores (Chumbo, Cromo, Bário, Cádmio), água resultante da combustão e contaminantes diversos como combustíveis (hidrocarbonetos leves) não queimados, poeira e outras impurezas. Ainda, pode conter produtos químicos que por vezes são inescrupulosamente adicionados ao óleo e seus contaminantes característicos [13-14]. Assim, o lubrificante perde suas propriedades e deixa de servir para a finalidade para a qual foi produzido, o que exige sua substituição para garantir a integridade e o bom funcionamento do motor ou equipamento. Importante destacar que o óleo lubrificante depois de perder suas propriedades é constituído por cerca de $80 \%$ a $85 \%$ de óleo básico, que pode ser recuperado [5].

\subsection{Problemática Ambiental do Óleo Usado ou Contaminado}

O OLUC é um resíduo perigoso e, por isso, deve ser corretamente manuseado, armazenado e destinado para evitar os vários problemas ambientais que podem surgir da sua disposição incorreta. Sendo derivado da contaminação do óleo lubrificante, ele mantém os principais constituintes deste (não são consumidos totalmente durante a sua vida útil), fato que os difere dos outros derivados do petróleo. Além dessa carga original de contaminantes, o OLUC apresenta outros componentes tóxicos resultantes da degradação do lubrificante, gerando compostos perigosos (dioxinas, ácidos orgânicos, cetonas e hidrocarbonetos policíclicos aromáticos-PAHs) à saúde humana e ao ambiente [5].

O fato de o OLUC ser um resíduo perigoso faz com que as responsabilidades sobre o seu gerenciamento sejam acrescidas, no sentido de dar uma destinação adequada ao resíduo. Outra propriedade do OLUC, não menos importante, está relacionada ao fato de não serem facilmente biodegradáveis e apresentarem diversos elementos tóxicos (cromo, cádmio, chumbo e arsénio) provenientes do desgaste do motor. Assim, quando o OLUC não é adequadamente descartado pode causar danos ao meio ambiente, contaminando o solo, curso d'água e quando queimado indiscriminadamente pode gerar emissões significativas de óxidos de metais e outros gases tóxicos [11].

O grau de poluição do OLUC é extremo ao se considerar a escala temporal ou espacial. Por exemplo, 1 litro de OLUC pode contaminar 1.000.000 litros de água, cobrindo uma superfície de $1.000 \mathrm{~m}^{2}$ com uma camada oleosa, degradando a qualidade de vida aquática e bioacumulando metais pesados [2,14]. Uma vez lançado num corpo d'água, o OLUC tem um tempo de degradação que varia de 10 a 15 anos, pois ele não se dissolve em água, nem se degrada facilmente. $\mathrm{O}$ OLUC altera as propriedades organolépticas da água, perturbando consideravelmente o processo de autodepuração desta, pois ocorre a formação de uma camada na superfície da água que a isola da atmosfera, impedindo a entrada de oxigênio e luz, colocando em risco a vida aquática [14-15].

O OLUC é tóxico à fauna aquática (pela presença de compostos como tolueno, benzeno, xileno, entre outros), aumenta a concentração de metais e, ainda, causa problemas de obstrução física dos tecidos dos animais, provocando-lhes asfixia e danos subletais por impregnação na pele, brânquias ou outras partes vitais. Além disso, sua disposição em redes de esgoto e águas pluviais pode causar o entupimento de difusores porosos de sistemas de aeração em estações de tratamento [1314]. Ele aparece como contaminante do ar atmosférico quando utilizado como combustível, causando graves problemas de contaminação resultante da sua combustão incompleta em motores. Entre os principais agentes poluidores do ar resultantes da queima desse tipo de óleo, destacam-se as grandes quantidades de material particulado (representado pela fuligem) contendo compostos de cloro, fósforo, enxofre e outros [13]. Portanto, a queima de OLUC, quando fonte energética, deve ocorrer em depurador de gases ou ser submetida a um prévio tratamento físico-químico para eliminar os possíveis contaminantes. 
No solo, o OLUC aparece muitas vezes como resultado do derramamento de depósitos subterrâneos. Uma vez descartado no solo, ele pode contaminar águas superficiais pelo escoamento superficial ou águas subterrâneas pela infiltração diminuindo a permeabilidade da superfície. O OLUC recobre o solo com uma película impermeável que destrói o húmus e a microflora, retirando toda a sua fertilidade e a capacidade de troca catiônica, além do fator estético, ou seja, deteriora as propriedades físicas e químicas do solo $[11,14]$.

\subsection{Legislação Brasileira sobre Óleos Lubrificantes/OLUC}

Devido ao óleo lubrificante pós-consumo tornar-se um resíduo perigoso, a sua destinação é alvo de regulamentação específica para proteger o meio ambiente dos possíveis danos que ele pode causar. Muitos são os países que oferecem uma destinação adequada a este resíduo, entre eles os da União Europeia (UE), EUA e alguns países da Ásia. Em relação ao Brasil, a classificação dos resíduos sólidos coloca o OLUC no grupo de resíduos sólidos de classe I - perigosos, em razão dos riscos potenciais de contaminação do meio ambiente e de seu efeito à saúde pública, em função de suas características de inflamabilidade, corrosividade, reatividade, toxicidade e patogenicidade [16]. Devido a isso, há necessidade de manusear e destinar mais rigorosamente o resíduo.

A legislação brasileira aplicável aos casos de infração relacionados à gestão e destinação adequada do OLUC é bastante vasta e depende principalmente dos desdobramentos que a inobservância da lei venha causar [5]. Assim, o infrator está sujeito às penalidades administrativas, penais e civis nas esferas ambientais, do consumidor, da indústria petrolífera, trabalhista, criminal, civil, entre outras. Além disso, o estado ou município pode ter leis específicas sobre o assunto a partir das particularidades de cada região. A análise da legislação voltada aos óleos lubrificantes encontra sua âncora num conjunto de atribuições definidas por leis e regulamentos que coordenam as atividades dos vários intervenientes do ciclo de óleo lubrificantes. Levando em consideração o potencial poluidor do OLUC, existe a necessidade de dar um destino ambientalmente seguro a ele. Os regulamentos e normas definidas nas resoluções do CONAMA, na ABNT NBR 10.004, na PNRS e Portarias Interministeriais trazem uma nova abordagem para $\mathrm{o}$ gerenciamento desse resíduo $[8,16]$.

Em relação ao OLUC, o CONAMA apresenta o instrumento legal com leis específicas e severas que regulamentam seu gerenciamento. Através da resolução NR. $362 / 05$, o órgão estabelece que o OLUC deve ser recolhido, coletado e ter destinação final de modo que não afete negativamente o meio ambiente. Esta destinação deve conduzir, através de processos tecnológicos, uma máxima recuperação dos constituintes iniciais do óleo lubrificante. A mesma resolução veda o descarte do OLUC em solos, subsolos, águas interiores e superficiais, em sistemas de esgotos ou em águas residuais. Ainda de acordo com essa resolução, o OLUC deve obrigatoriamente ser regenerado. O processo tecnológico industrial a se aplicar na regeneração é o rerrefino, um método considerado ambientalmente mais seguro, que consiste num processo industrial de remoção de contaminantes, produtos da sua degradação e aditivos, conferindo-lhe características e propriedades do óleo básico ou ainda um processo tecnológico de eficácia ambiental equivalente ou superior [8]. Além do rerrefino, a legislação possibilita alternativas de processamento do OLUC para obtenção de produtos consumidos exclusivamente pelos respectivos geradores industriais, sem as exigências técnicas de um processo de rerrefino (combustíveis ou lubrificantes industriais). A tabela 1 apresenta as principais leis, normas e regulamentos relacionados ao gerenciamento de OLUC.

Tabela 1: Principais leis, normas e regulamentos para o gerenciamento de OLUC.

\begin{tabular}{|c|c|c|}
\hline \multicolumn{2}{|r|}{ Diretiva } & Descrição \\
\hline 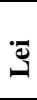 & $\begin{array}{ll}\text { Lei } & \mathrm{n}^{\mathrm{o}} \\
12.305 / 10 & \end{array}$ & $\begin{array}{l}\text { Dispõe da obrigatoriedade da logística reversa para os } \\
\text { óleos lubrificantes com regras e metodologias definidas } \\
\text { nos acordos setoriais. Ela institui a PNRS }\end{array}$ \\
\hline \multirow{3}{*}{ 导 } & $\begin{array}{l}\text { Res. } \\
\text { CONAMA n } \\
\text { 362/05 }\end{array}$ & $\begin{array}{l}\text { Determina a coleta e destinação de todo óleo lubrificante } \\
\text { usado ou contaminado e, as obrigações ambientais de } \\
\text { cada agente do setor. }\end{array}$ \\
\hline & $\begin{array}{l}\text { Res. ANP } n^{\circ} \\
19 / 09\end{array}$ & $\begin{array}{l}\text { Estabelece os requisitos necessários à autorização para o } \\
\text { exercício da atividade de rerrefino de óleo lubrificante } \\
\text { usado ou contaminado e sua regulação. }\end{array}$ \\
\hline & $\begin{array}{l}\text { Res. ANP } n^{\circ} \\
20 / 09\end{array}$ & $\begin{array}{l}\text { Estabelece os requisitos necessários à autorização para o } \\
\text { exercício da atividade de coleta de óleo lubrificante usado } \\
\text { ou contaminado e sua regulação. }\end{array}$ \\
\hline \multirow{3}{*}{ : } & Port. MMA $\mathrm{n}^{\circ}$ & Institui o grupo de monitoramento permanente da Res. \\
\hline & $31 / 07$ & $\begin{array}{l}\text { CONAMA } 362 / 05 . \text { Constituído pelo MMA, MME, } \\
\text { Ministério das Cidades, IBAMA, ANP, ABEMA, } \\
\text { ANAMMA, } \quad \text { SINDICOM, } \\
\text { SIMEPETRO, ONGs Ambientalistas. }\end{array}$ \\
\hline & $\begin{array}{l}\text { Port. } \\
\text { Interministeri } \\
\text { al } \\
\text { MME/MMA } \\
n^{\circ} 59 / 12\end{array}$ & $\begin{array}{l}\text { Estabelece as diretrizes para o recolhimento, coleta e } \\
\text { destinação dos OLUC, determina os percentuais mínimos } \\
\text { de coleta a serem atendidos pelos produtores e } \\
\text { importadores de lubrificantes acabados, por regiões e no } \\
\text { País. }\end{array}$ \\
\hline
\end{tabular}

Fonte: Adaptado de $[8,17]$

Assim, chama-se à responsabilidade compartilhada aos autores da cadeia produtiva e de consumo, desde o produtor, o importador e o revendedor de óleo lubrificante acabado, até aos geradores de OLUC para a necessidade de coleta e encaminhamento do resíduo ao destino legalmente definido, no caso, uma indústria de rerrefino $[8,17]$.

Apesar de ser um resíduo tóxico, o OLUC apresenta valor econômico, pois contém hidrocarbonetos que podem ser recuperados e representam um ganho econômico, uma vez que o óleo básico retirado deste pode receber novos aditivos e retomar as propriedades de óleo lubrificante. Devido a isso, existem vários intervenientes na sua cadeia de gerenciamento, cabendo à Agência Nacional de Petróleo, Gás Natural e Biocombustíveis (ANP) a responsabilidade de cadastrar todos os intervenientes, desde compradores, coletores e empresas de rerrefino. Esta medida ajuda a diminuir a pressão sobre a 
intensa exploração do petróleo e consequente diminuição da carga de poluentes lançados ao meio ambiente [17].

\subsection{Caracterização do Ciclo de vida do Óleo Lubrificante Usado ou Contaminado}

O ciclo de vida do OLUC é caracterizado por um conjunto de atores. Aos revendedores, aqueles que direta ou indiretamente comercializam óleos lubrificantes (postos de serviços, oficinas, supermercados, lojas de autopeças, atacadista etc.), a legislação atribui um papel de ligação entre os consumidores e os agentes da cadeia de rerrefino, os coletores. Os revendedores têm uma dupla responsabilidade. Por um lado, garantir a existência de um OLUC não contaminado e pronto para o rerrefino e, por outro, como agentes produtores e importadores, têm a obrigação de garantir o recolhimento seguro e a entrega aos coletores autorizados. Por sua vez, o coletor, pessoa jurídica licenciada pelo órgão ambiental do estado e autorizada pela ANP, tem a função de coletar e entregar o OLUC às empresas de regeneração [5]. A figura 2 mostra o fluxo do óleo lubrificante na cadeia de consumo/produção e os destinos finais durante o seu ciclo de vida.

O Sindicato Nacional da Indústria do Rerrefino de Óleos Minerais (SINDIRREFINO) registra as contribuições de cada setor interveniente na colocação do óleo lubrificante no mercado brasileiro através da produção e/ou fornecimento do óleo básico. Da quantidade total de óleo básico usado para a produção do óleo lubrificante comercializado no Brasil, cerca de $65 \%$ é de produção nacional: $45 \%$ proveniente de refinarias de petróleo bruto e $20 \%$ do rerrefino do OLUC. Nota-se também que o Brasil continua sendo um grande importador de óleo básico, matéria-prima para fabricação do óleo lubrificante; cerca de $35 \%$ é importado [18].

\subsection{Vias de Tratamento do Óleo Lubrificante Usado ou Contaminado. O Rerrefino}

O valor econômico e calorífico do OLUC constituem os principais argumentos para o seu tratamento. Considerandose a composição do OLUC (80-85\% composto de óleo básico), cada país ou região define o destino legal a dar a este tipo de resíduo. Por exemplo, a UE define os diferentes níveis de tratamento aplicados ao OLUC baseando-se nos seus valores econômicos e caloríficos. Entre eles, a regeneração e queima direta correspondem a $70 \%$ da massa do OLUC coletado enquanto o reprocessamento e a recuperação (utilizada para óleos hidráulicos) são responsáveis pelos restantes $30 \% \mathrm{em}$ massa do OLUC coletado [19].

As técnicas mais usadas mundialmente para o tratamento do OLUC são a regeneração (pelo rerrefino) e aproveitamento energético, correspondendo a $60 \%$ da massa da quantidade total de OLUC derivado dos diversos sistemas de reaproveitamento. Enquanto que o reprocessamento e a reutilização correspondem a cerca de $30 \%$ de massa $[19,20]$. As operações de regeneração de OLUC podem ser divididas em processos de recuperação e de rerrefino.

$\mathrm{O}$ processo de recuperação utiliza as diferenças entre as propriedades físicas dos componentes para separá-los (através da sedimentação, aquecimento, desidratação, filtração e centrifugação). Por sua vez, no rerrefino, ocorre um tipo de tratamento físico-químico que consiste em remover todos os contaminantes e aditivos previamente incorporados ao óleo básico (destilação, extração por solvente, hidrotratamento ou ultrafiltração). Além desses dois processos comuns, existem outros que visam tratar o OLUC de forma a produzir um material que posteriormente pode ser usado como combustível ou para outros fins $[4,20]$.

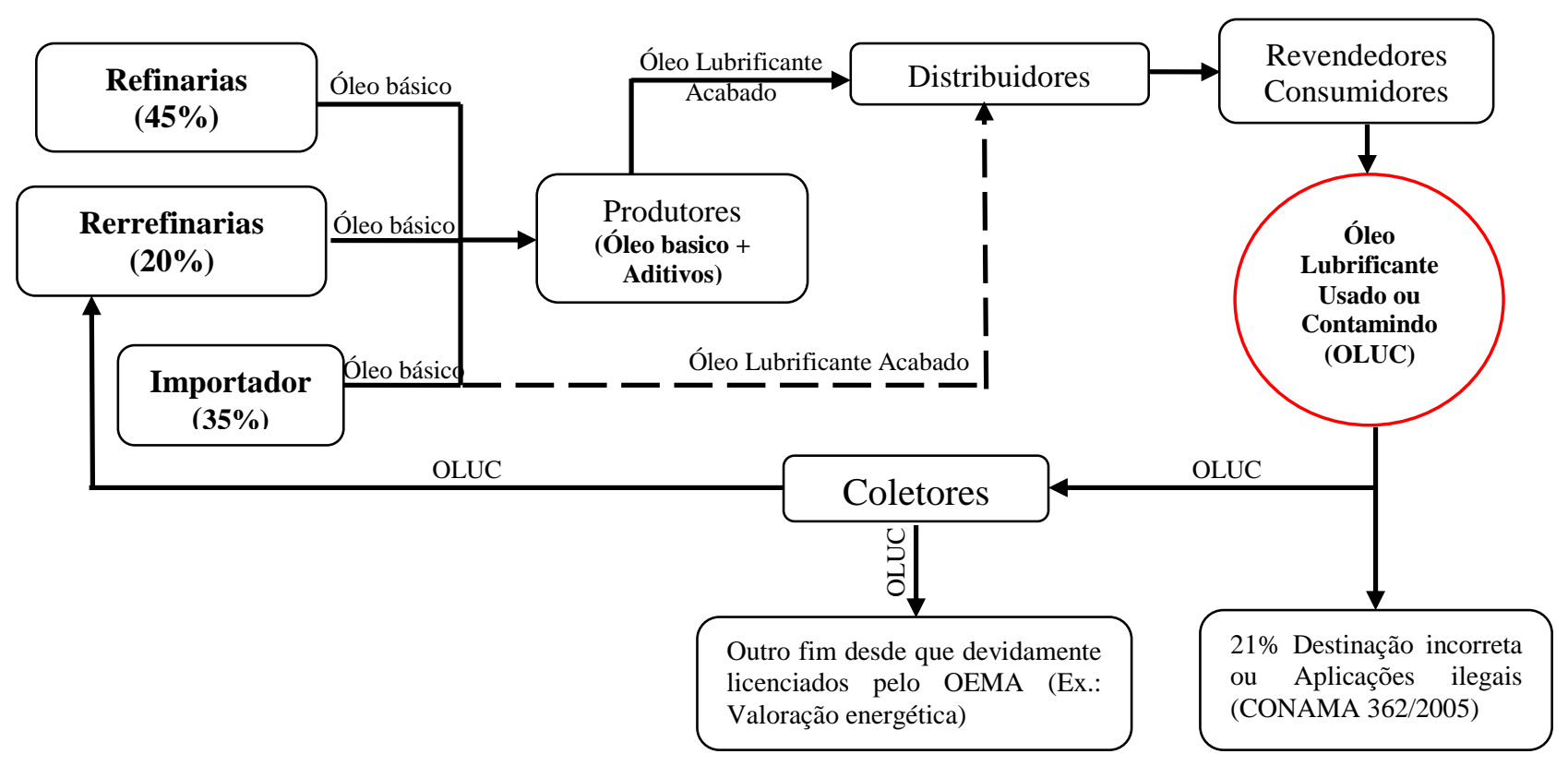

Figura 2: Fluxograma do ciclo de vida do óleo lubrificante. Fonte: Adaptado de [13,18] 
A queima de OLUC para aproveitamento energético é uma alternativa adotada por diversos países no mundo como os da UE, EUA e certos países da Ásia, porém cada um com especificações definidas pelas suas legislações, podendo ser utilizado em cimenteiras $(35 \%$ de cimenteiras mundiais usam OLUC como fonte energética), em alto forno como substituto do coque. Há outros usos dado ao OLUC em diferentes países, tais como: em fábricas de tijolo (Bélgica), em fornos de cal (Espanha), em instalações de conversão de OLUC em combustíveis de navios (China), em incineradoras de resíduos (Malta), em instalações de produção de asfalto (EUA), entre outros [20]. A figura 3 mostra as diversas tecnologias de tratamento mundialmente aplicadas ao OLUC. A existência de diversas tecnologias utilizadas no tratamento ou reaproveitamento do OLUC propiciou a existência de estudos relacionados à qualidade dessas tecnologias, como é o caso do estudo de MONIER \& LABOUZE, em que se chama atenção às duas formas básicas de destinar o OLUC. Uma delas consiste em converter o OLUC em óleo básico que é usado para produzir óleos lubrificantes - a regeneração [21].
A outra, o reaproveitamento, é o processo que consiste em tratar o OLUC de forma a obter um material que seja, posteriormente, usado para valoração energética. Em ambos os casos, a transformação do OLUC é sempre precedida por uma limpeza, processo que envolve a remoção de impurezas e todas as substâncias contaminantes. Dentre as diversas alternativas de tratamento do OLUC, o rerrefino constitui a tecnologia mundialmente mais usada $[19,22]$.

A atividade de rerrefino no Brasil é caracterizada por ser efetuada com base em diversificada tecnologia e cada empresa de rerrefino adota a tecnologia conveniente não só ao seu capital financeiro de instalação da tecnologia, mas também à quantidade de OLUC rerrefinado [17]. A tecnologia de rerrefino é caracterizada por apresentar diferentes etapas tecnológicas dependendo das especificidades legislativas e comerciais exigidas em cada local, porém, de forma generalizada, todos os processos de rerrefino apresentam etapas comuns (pré-tratamento e fracionamento) [23].

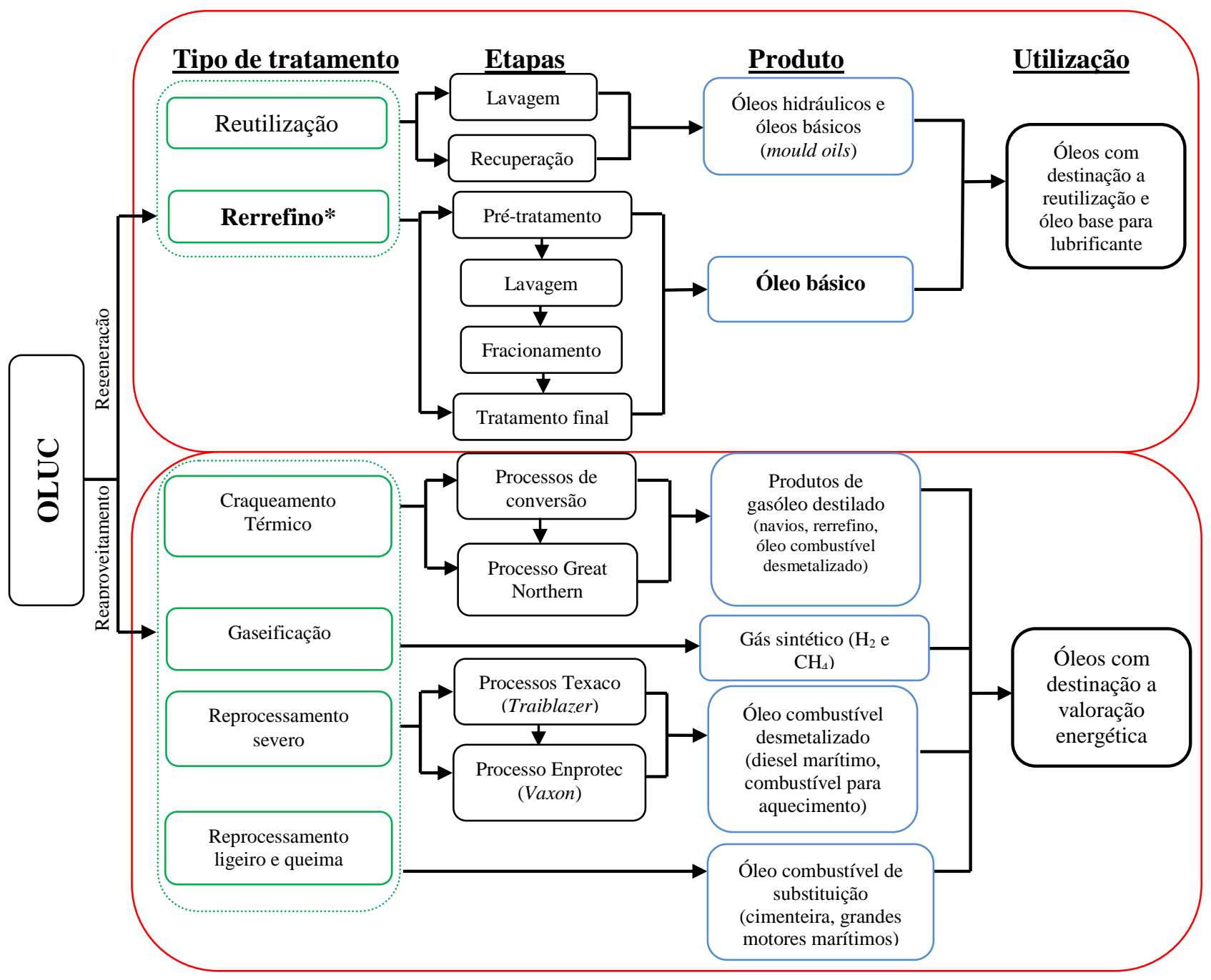

* tecnologia de tratamento de OLUC derivados de óleos para motores sem cloro, óleos hidráulicos, óleos minerais hidráulicos, óleos minerais diatérmicos (de acordo com a classificação da API). 


\section{Metodologia}

A metodologia utilizada para a realização da pesquisa baseou-se numa avaliação do sistema de gerenciamento do OLUC, destacando todos os processos, e das tecnologias aplicadas no seu ciclo de vida. O trabalho teve como perspectiva, ainda, a avaliação de possíveis impactos ambientais e socioeconômicos, que podem servir para dar suporte na tomada de decisões sobre o sistema de gerenciamento adotado para este tipo de resíduo perigoso. A fase de análise integrou uma abordagem ambiental, econômica e social do processo de gerenciamento do OLUC no seu ciclo de vida. Para a efetivação dos pressupostos do estudo, houve a necessidade de agregar um conjunto de informações relacionadas à distribuição geográfica das indústrias de rerrefino nas diferentes regiões do país. Os dados foram obtidos a partir de quatro visitas técnicas e entrevistas realizadas nas três diferentes etapas do processo de gerenciamento do OLUC, e também através das informações obtidas na Fundação Estadual de Proteção Ambiental (FEPAM), na Agência Nacional de Petróleo (ANP) e no SINDIRREFINO (licenças de operação e relatórios institucionais, de 2012-2015). Para isso, foram elaborados três guias de entrevistas:

(i) Guia 1: Para Empresas de Geração de OLUC este guia foi elaborado com a finalidade de obter informações sobre o processo de geração de OLUC, suas particularidades em relação à segurança dos colaboradores e os cuidados ambientais que devem caracterizar essa etapa. Procurou-se ainda obter informações sobre a quantidade e o mecanismo de gerenciamento de OLUC nessa fase. Para isso foram definidos seis pontos geradores (três postos de combustíveis e três oficinas mecânicas). Não se definiu nenhuma indústria como ponto de coleta de informação de geração de OLUC, em virtude da pequena quantidade de OLUC produzida nesses locais, quando comparado com outras fontes. Como refere GOSALIA, a maior quantidade de OLUC gerado no mundo é proveniente da troca em veículos automotivos; cerca de $3 / 5$ da geração anual [9].

(ii) Guia 2: Para Empresas de Coleta de OLUC - este guia foi elaborado com a finalidade de obter informações sobre o processo de coleta de OLUC e todas as questões que estão envolvidas no gerenciamento do OLUC desde o local de geração até aos centros de transbordo ou até ao portão da indústria de rerrefino. Nesta fase, deu-se particular atenção a aspectos relacionados aos possíveis impactos socioambientais que advém desta fase do gerenciamento do OLUC.

(iii) Guia 3: Para Empresas de Rerrefino de OLUC - com este guia, obteve-se informações sobre o processo tecnológico de rerrefino de OLUC, suas particularidades, insumos para o processo, a produtividade do óleo básico, e o gerenciamento dos resíduos gerados nesse processo.
O conjunto de instrumentos para a coleta de dados foi aplicado entre Março e Setembro de 2016. A aplicação foi precedida de visitas técnicas, testagem e aprovação dos instrumentos por profissionais ligados ao processo de gerenciamento do OLUC. O público alvo foi definido em função das atividades desenvolvidas em cada uma das etapas deste ciclo. Esse público foi agrupado por: colaboradores de postos de combustíveis e de oficinas mecânicas, colaboradores das empresas de coleta e técnicos da indústria de rerrefino de OLUC.

\section{Resultados e discussões}

O mapa da figura 4 mostra a situação da distribuição geográfica dos centros de coleta e das indústrias responsáveis pelo rerrefino do OLUC no Brasil.

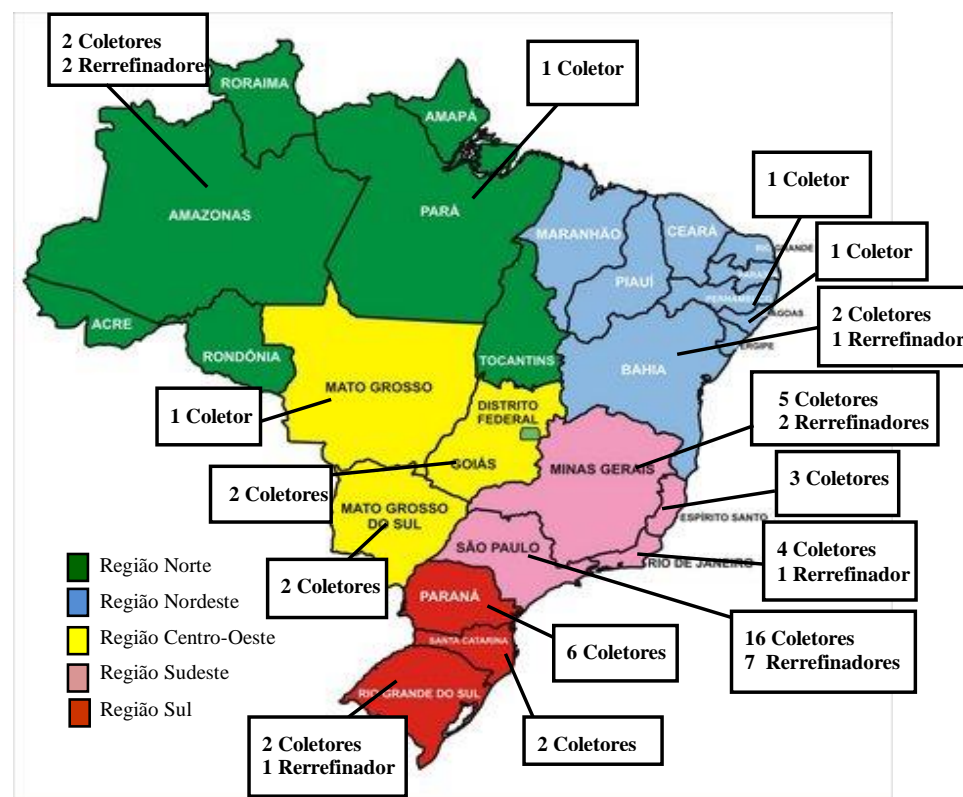

Figura 4: Distribuição dos centros de coleta e rerrefinarias de OLUC pelo Brasil.

Fonte: adaptado de [11,17]

O mapa foi elaborado a partir do conjunto de informações disponibilizadas nos sítios eletrônicos da ANP e do SINDIRREFINO. Pode-se observar que a região Sudeste apresenta maior número de centros de coleta de OLUC e um maior número de rerrefinarias, totalizando 10 (4 não associadas ao SINDIRREFINO), e um total de 28 centros de coleta (12 não associados). A região Sul apresenta 10 centros de coleta de OLUC (1 não associado) e 1 rerrefinaria. A região Nordeste possui 4 centros de coleta de OLUC e 1 rerrefinaria, enquanto a região Norte possui 3 centros de coleta ( 2 não associados) e 2 rerrefinarias (não associadas ao SINDIRREFINO). Por fim a região Centro-Oeste conta com 5 centros de coleta de OLUC (2 
não associados) e nenhuma rerrefinaria [11,17]. É importante salientar que as empresas não associadas ao SINDIRREFINO realizam suas atividades com licenças atribuídas pela ANP e Orgão Estadual de Meio Ambiente (OEMA), por isso, elas não gozam do conjunto de benefícios do associativismo que caracteriza o sindicato (cursos, encontros técnicos de avaliação, outros).

De acordo com o SINDIRREFINO, o Brasil conta com um total de 14 empresas de rerrefino de OLUC e 24 empresas que se dedicam a coleta de OLUC. A base teórica para o estudo e, sobretudo, da análise de dados baseou-se na diversidade de processos tecnológicos dos centros de coleta e das indústrias de rerrefino distribuídas pelo país [18]. O sistema de gerenciamento de OLUC, no Brasil, pode ser considerado satisfatório, pois tem se registrado uma evolução que pode ser equiparada a outros sistemas de gerenciamento do OLUC, como são os casos do europeu ou americano. Isso é justificado pelo nível de cobertura, sobretudo, na coleta do OLUC, tendo ultrapassado a meta recomendada pela resolução 362/05 do CONAMA e pela UNITED NATIONS ENVIRONMENTAL PROGRAMME (UNEP), que determinam um volume mínimo de $30 \%$ do OLUC gerado. Em relação a isso, o nível de coleta do OLUC no Brasil pode ser equiparado ao de alguns países da UE, como são os casos da Espanha, 47\%, Luxemburgo, 39\%, Grécia, 37\% [2,8,10].

Apesar de o OLUC ser um produto economicamente valioso, passível de reutilização, ele nem sempre é corretamente reaproveitado, embora exista, uma grande variedade de metodologias para sua regeneração e reaproveitamento, através de diversificados sistemas de processamento e tratamento. A partir do percentual de massa do óleo básico no OLUC e a necessidade de minimização da geração de resíduos, o CONAMA definiu o processo de rerrefino como o principal processo de reaproveitamento do OLUC no Brasil. Isso ocorreu devido à implementação do princípio de "poluidor-pagador", ao responsabilizar as empresas produtoras e importadoras de óleos lubrificantes acabados pela coleta do OLUC, o que ampliou a responsabilidade de cada um dos constituintes dessa cadeia. $\mathrm{O}$ volume mínimo de coleta é estabelecido por percentual incidente sobre o volume total de óleo lubrificante comercializado, atualmente correspondente a 30\% [8,19]. A adoção de uma legislação mais flexível que desvincula o coletor do regenerador favoreceu a entrada de novos coletores, contribuindo para a expansão da rede de coleta do OLUC [22]. Assim, o rerrefino passou a ser o destino legal para o reaproveitamento do OLUC.

Parte do OLUC produzido no Brasil é corretamente coletado e destinado, com vista a sua regeneração e recuperação do óleo básico. No período de 2013 a 2015, houve um aumento da cobertura nacional em relação à coleta do OLUC passando de $37,4 \%$ para $38,5 \%$ em 2015, resultado de uma produção média anual próxima de um bilhão de litros de
OLUC [17,18]. As principais fontes de geração de OLUC no Brasil são os pequenos produtores (as oficinas urbanas de troca de óleos lubrificantes de automóveis, os postos de combustíveis, garagens, aeroportos e embarcações) e as grandes indústrias, que juntos são responsáveis por cerca de $80 \%$ do OLUC produzido. Na maioria delas, existem procedimentos regulamentados para a realização da atividade com objetivo de minimizar os impactos ambientais e a saúde ocupacional do manuseamento do OLUC.

A logística reversa de OLUC, uma iniciativa legal no território brasileiro, orienta o processo de pós uso de óleo lubrificante [8]. Assim, após a geração, o OLUC é coletado e armazenado em tanques ou contêineres específicos que se caracterizam por apresentar estruturas equivalentes a diques de contenção (muretas) com a finalidade de conter o óleo em caso de acidentes. A coleta do OLUC é realizada por uma pessoa jurídica, licenciada pelo órgão ambiental (do estado ou município) e autorizada pela ANP para exercer a atividade de coleta e destinar a empresa de regeneração do OLUC. Segundo a ANP, esta atividade deve ser realizada por veículos específicos, que possuam equipamentos de identificação e sinalização, bombas de sucção para retirada do OLUC dos tanques [17]. De acordo com o SINDERREFINO, entidade sindical que congrega a maioria das rerrefinadoras, o serviço de coleta do OLUC abrange a maioria dos municípios brasileiros, existindo atualmente cerca 50 centros de coleta distribuídos pelas diferentes regiões do Brasil como mostra a Tabela 2.

Tabela 2: Evolução anual de coleta de OLUC nas diferentes regiões do Brasil

\begin{tabular}{|c|c|c|c|c|c|c|c|}
\hline \multirow[b]{2}{*}{ Região } & \multirow{2}{*}{$\begin{array}{c}\text { Centro } \\
\text { de } \\
\text { coleta }\end{array}$} & \multicolumn{6}{|c|}{ Projeção de coleta anual } \\
\hline & & \multicolumn{2}{|c|}{2013} & \multicolumn{2}{|c|}{2014} & \multicolumn{2}{|c|}{2015} \\
\hline Norte & 03 & \multicolumn{2}{|c|}{$28 \%$} & \multicolumn{2}{|r|}{$30 \%$} & \multicolumn{2}{|c|}{$31 \%$} \\
\hline Nordeste & 04 & \multicolumn{2}{|c|}{$28 \%$} & & $30 \%$ & \multicolumn{2}{|c|}{$32 \%$} \\
\hline $\begin{array}{l}\text { Centro- } \\
\text { Oeste }\end{array}$ & 05 & \multicolumn{2}{|c|}{$33 \%$} & & $34 \%$ & \multicolumn{2}{|c|}{$35 \%$} \\
\hline Sudeste & 28 & \multicolumn{2}{|c|}{$42 \%$} & & $42 \%$ & \multicolumn{2}{|c|}{$42 \%$} \\
\hline Sul & 10 & \multicolumn{2}{|c|}{$36 \%$} & & $37 \%$ & \multicolumn{2}{|c|}{$37 \%$} \\
\hline \multirow[b]{2}{*}{ Total } & $\begin{array}{l}\text { Centros } \\
\text { de coleta }\end{array}$ & $\%$ & $\begin{array}{c}\begin{array}{c}\text { Coleta } \\
\text { (L) }\end{array} \\
\text { ons }\end{array}$ & $\%$ & $\begin{array}{c}\text { Coleta } \\
\text { (L) }\end{array}$ & $\%$ & $\begin{array}{c}\begin{array}{c}\text { Coleta } \\
\text { (L) }\end{array} \\
\end{array}$ \\
\hline & 50 & 37,4 & $372 \times 10^{6}$ & 38,1 & $379 \times 10^{6}$ & 38,5 & $383 \times 10^{6}$ \\
\hline
\end{tabular}

Importante destacar que cerca de $21 \%$ do resíduo tem destinação incorreta ou aplicações ilegais de acordo com o estabelecido pela resolução 362/05 do CONAMA. Além disso, cerca de $40 \%$ do OLUC gerado é dispensado de coleta para o rerrefino, valendo a este um destino ambientalmente seguro, desde que legalmente estabelecido e licenciado pelo OEMA. Esse fato representa motivo de preocupação, quer sob o aspecto ambiental, quer sob o aspecto econômico, uma vez que o OLUC corresponde a uma fonte de matéria-prima não renovável e um resíduo ambientalmente perigoso [17,18].

A produção, o consumo do óleo lubrificante e as formas de reaproveitamento ou descarte do OLUC no Brasil podem ser resumidos pelo fluxograma da figura 5. Nele são 
apresentados os resultados da conjugação de informações obtidas através das entrevistas, observações das etapas de gerenciamento do OLUC e informações obtidas da ANP e do SINDIRREFINO.

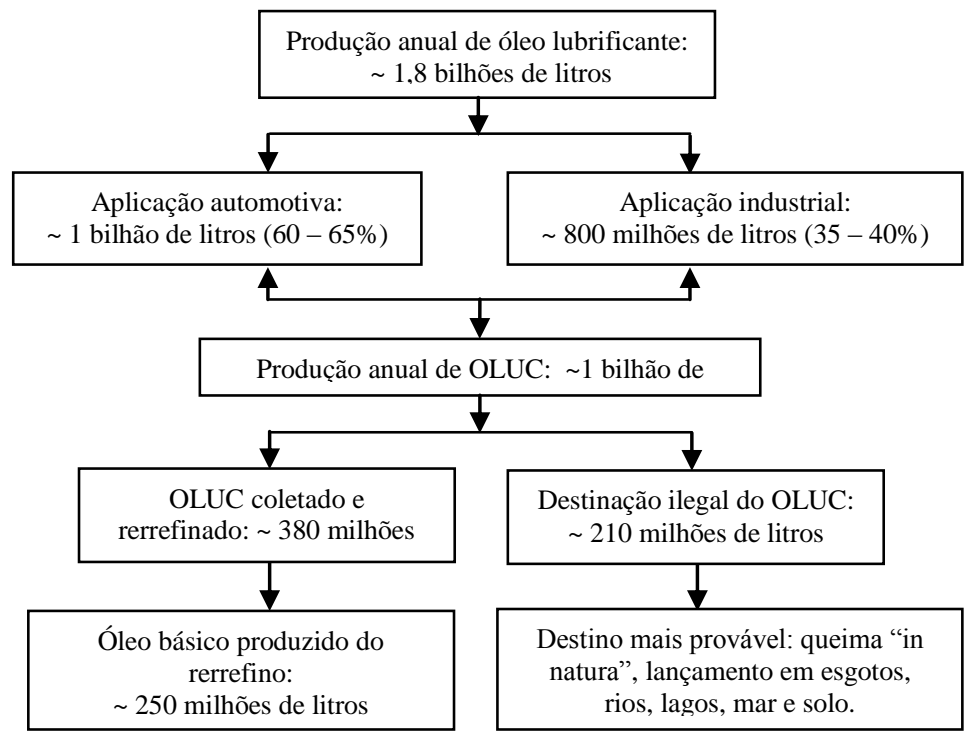

Figura 5: Gerenciamento do óleo lubrificante no Brasil.

A atividade de rerrefino no Brasil é caracterizada por ser efetuada com base numa tecnologia de reconhecido mérito internacional, em virtude disso os produtos obtidos desse processo são caracterizados por apresentarem qualidades específicas estabelecidas internacionalmente [15]. O processo de rerrefino é um processo industrial que visa essencialmente produzir óleo básico e é caracterizado por um conjunto diversificado de tecnologias. Mundialmente a indústria de rerrefino é caracterizada por um conjunto de processos tecnológicos que tendem cada um a produzir um determinado tipo de óleo básico de acordo com as especificações da legislação exigida no país ou região. $\mathrm{Na} \mathrm{UE}$, as tecnologias frequentemente empregadas são o processamento via destilação a vácuo/tratamento com argila/tratamento químico/tratamento com hidrogénio [19]. Nos EUA, o rerrefino como processo de reaproveitamento de OLUC constitui $45 \%$ do total do OLUC coletado. O processo de rerrefino usualmente empregado nos EUA é o processamento via Destilação a vácuo/tratamento com hidrogénio [21]. O parque industrial de rerrefino brasileiro é composto por três tipos diferentes de tecnologias [17]:

- Processamento via sistema Ácido/Argila com "termo craqueamento" - cujo produto principal é óleo básico pesado e óleo spindle (designação técnica de uma das frações do óleo básico). Essa é a tecnologia mais comum nas rerrefinarias brasileiras. Seus inconvenientes são o alto custo de produção pelo consumo excessivo de ácido sulfúrico e argila ativada, a geração de grande quantidade de borra ácida e um rendimento que não passa de $60 \%$. As principais vantagens residem no fato de possibilitar o rerrefino de pequenas quantidades de OLUC e requerer menores custos inicias de investimento.

- Processamento via sistema de Destilação a Flash ou evaporação pelicular - cujos produtos são o óleo spindle, o óleo básico leve e o médio. Essa tecnologia não é comum em refinarias brasileiras. Ela é caracterizada por ser relativamente mais eficiente que a anterior, com um rendimento próximo de $70 \%$, porém seu custo de instalação é maior.

- Processamento via sistema por Extração a solvente seletivo de propano (desasfaltamento com propano) - cujos produtos principais são o óleo médio leve, médio e spindle. Essa tecnologia é caracterizada por apresentar um rendimento acima de $70 \%$, por isso considerado mais eficiente que as anteriores.

O Sistema Ácido Argila com "termo craqueamento", embora em desuso em diversos países desenvolvidos por razões econômicas, tecnológicas, produtivas e, sobretudo, devido aos problemas causados pela geração de resíduos ácidos, continua sendo utilizado em algumas rerrefinarias no Brasil. Tal processo conduz a geração de um óleo básico de boa qualidade. O principal problema dessa tecnologia é a geração de borra ácida oleosa que pode chegar à ordem de aproximadamente 35.000 toneladas/mês para um volume equivalente a 405 milhões de litros de OLUC rerrefinado (cada litro de OLUC rerrefinado gera 77,7 gramas de borra ácida). Em contrapartida, o processo apresenta baixo custo de manutenção e é capaz de rerrefinar OLUC de baixa qualidade e com diversos contaminantes. A sua baixa produtividade está relacionada ao processo de execução em batelada e pelo fato de possuir um arraste de óleo alto de cerca de $10 \%$ do volume [17-19,22].

\section{Conclusões}

O estágio atual do gerenciamento do OLUC no Brasil pode ser considerado eficiente pelo fato de ter atingido um nível acima do estabelecido pela ANP e pelo SINDIRREFINO, em função do óleo lubrificante comercializado. Por outro lado, embora exista um conjunto de instrumentos legais que atribui deveres e responsabilidades a cada um dos atores envolvidos na cadeia de gerenciamento do OLUC, existe uma quantidade considerável, cerca de $21 \%$ do volume do OLUC gerado, que não é coletado, isto é, não é gerado pelas empresas geradoras do OLUC e consequentemente são ilegalmente descartados em corpos d'água, solo ou ar.

O sistema de gerenciamento do OLUC é caracterizado por contribuir socioeconomicamente para todos os intervenientes da sua cadeia de gerenciamento. O conjunto de atividades desta cadeia contribui para a geração de mais postos de trabalho proporcionando o aumento da renda familiar para os intervenientes das diversas etapas desta cadeia de gerenciamento. Este sistema permite dar valor econômico a um 
resíduo que é bastante prejudicial ao meio ambiente. Os geradores vendem o OLUC às empresas de coleta e estas às empresas de Rerrefino, sendo que o valor da venda é definido pelo SINDIRREFICO, com aprovação da ANP.

A existência de diversas tecnologias de tratamento/reaproveitamento do OLUC para produção de óleo básico permite abranger as grandes quantidades geradas por regiões. Em função da quantidade de OLUC gerada e da disponibilidade de capital financeiro a investir, define-se a tecnologia para a implantação da planta de rerrefino. O Brasil possui diversas tecnologias para o rerrefino do OLUC, desde a menos eficiente ambientalmente a mais exigente em relação ao capital de investimento financeiro. Para a implantação de uma rerrefinaria são conjugados os aspectos econômicos e ambientais.

O estudo é mais uma contribuição que poderá ser utilizada, através dos seus resultados, fluxogramas e discussões, como elementos para realização de estudos futuros, focando o gerenciamento do OLUC e particularmente para uma futura aplicação da metodologia de Avaliação de Ciclo de Vida desse produto, considerando-se as definições apresentadas em relação aos limites dos sistemas do ciclo de vida do OLUC. Isso possibilita a realização do inventário e consequente análise dos impactos ambientais, sociais e econômicos do ciclo de vida do OLUC.

\section{Agradecimentos}

Os autores agradecem ao $\mathrm{CNPq}$ pela disponibilidade de bolsa de apoio a pesquisa.

\section{WASTE USED LUBE OILS MANAGEMENT SYSTEM ASSESSMENT IN BRAZIL}

\section{ABSTRACT}

The increasing awareness of technological development accords to sustainability issues and it is an important milestone in ensuring socio-economic and environmental satisfaction. The National Solid Waste Policy (PNRS) and the Resolution $362 / 2005$ of the National Council for the Environment (CONAMA) are some of the legal instruments that guarantee the partial materialization of this awareness. This study evaluates the current stage of the Waste Used Lube Oil (WULO) management system; it discusses the current legislation for the sector and the technologies used for its reuse. The proper management of the WULO is crucial to avoid the set of environmental issues resulting from its inadequate disposal, such as water, soil and air contamination. Brazil is currently the world's sixth largest consumer of lubricants, therefore, the sixth largest WULO producer, since the country produces about one million liters/year. The country reached the collection capacity of $38.5 \%$, considered satisfactory according to the minimum collection goal established by UNEP and the
362/2005 CONAMA Resolution. The resulting supports the need to improve the WULO management system, regarding socio-economic and environmental issues. There is an urgent necessity to inspect and monitor the activity in order to minimize the impacts caused by WULO inadequate disposal.

Keywords: WULO. Management. Re-refining.

\section{Referências}

[1] GABRIEL, L.; SCHNEIDER, A; SKROBOT, F.; SOUZA, M. Uma Análise da Indústria Automobilística no Brasil e a Demanda de Veículos Automotores: Algumas evidências para o período recente. In: IV encontro Internacional da Associação Keynesiana Brasileira (AKB), JEL: L00; L13 and L62 2011, Rio de Janeiro, 2011, p. 1 - 25 .

[2] RAC, A; VENCL, A. Ecological and technical aspects of the waste oils influence on environmental. In: the Annals of University "Dunãrea de Jos" of Galati. Fascicle VIII, Tribology 2012 (XVIII). Issue 1, ISSN 1221-4590.

[3] GUERIN, T. F. Environmental liability and life-cycle management of lubricating oils. Journal of Hazardous Materials, v. 160, p. 256 - 264, 2008.

[4] HAMILTON, S. F; SUNDING, D. L. Optimal Recycling Policy for Used Lubricating Oils: The case of California's used oil management policy. Environ Research Eco, v. 62, p. 3-17, 2015.

[5] SOHN, H. Guia básico: Gerenciamento de óleos lubrificantes usados ou contaminados. GMP/SENAI. São Paulo, 2011

[6] KUCZENSKI, B.; GEYER, R; ZINK, T; HENDERSON, A. Material flow analysis of lubricating oils uses in California. Resources, Conservations and Recycling, v. 93 , p. $59-66,2014$

[7] CASTRO, M; Da SILVA, N.; MARCHAND, G. Developing indicators for sustainable management of solid waste in Iranduba, Manacapuru and Novo Airao municipalities, Amazon, Brazil. Engenharia Sanitária e Ambiental, v. 20, n. 3 , p. $415-426,2015$

[8] CONSELHO NACIONAL DO MEIO AMBIENTE - CONAMA. Resolução 362/2005: Regulamentação da Coleta, Transporte, Armazenamento e Destinação Adequada dos Óleos Lubrificantes Usados e Contaminados. Publicada no DOU n. 121. Seção 1, p. 128 - 130, de 27 de junho de 2005.

[9] GOSALIA, A. Sustainability and the Global Lubricant Industry. The $16^{\text {th }}$ ICIS World Base Oil \& Lubricant conference. London, 2012.

[10] UNITED NATIONS ENVIRONMENTAL PROGRAMME - UNEP Global Waste Management Outlook. Disponível em: http://unep.org/ietc/Portals/136/Publications/Waste\%20Management/GWMO\% 20report/GWMO_report.pdf. Acesso em 12/08/2015.

[11] SINDICATO NACIONAL DA INDÚSTRIA DE RERREFINO DE ÓLEOS MINERAIS - SINDIRREFINO [internet]. Logística reversa de óleos lubrificantes e rerrefino. São Paulo; 2016. Disponível em: http://www.sindirrefino.org.br. Acesso em 12/03/2016.

[12] SILVA, T. A.; De OLIVEIRA, K. M. Descarte de Óleos Lubrificantes e suas Embalagens: Estudo de caso dos postos de gasolina e estações de serviço da cidade da Itucutaba, Estado de minas Gerais. OBSERVATORIUM: Revista Eletrônica de Geografia, v.3, n.7, p. 101 - 104, 2011. 


嘈 $1 /$ IECNO-LOGICA

[13] CENTRO NACIONAL DE TECNOLOGIAS LIMPAS - SENAI. Projeto Programa Piloto para a Minimização de Impactos Gerados por Resíduos Perigosos: Documento 3 - Gestão de óleo lubrificante automotivo usado em oficinas automotivas. Pernambuco, 2006.

[14] MARTINS, C. R. Avaliação de estrutura dos postos de revenda de combustíveis do Distrito Federal quanto á geração de resíduos aliada à análise da sua citotoxicidade e genotoxicidade. 139 f. Tese (Programa de PósGraduação em Biologia Animal - Tese) - Universidade de Brasília. 2007.

[15] CANCUMANI, G. A. L. Óleos Lubrificantes Usados: Um estudo de caso da Avaliação do Ciclo de Vida do sistema de rerrefino no Brasil. 157 f. Tese (Programa de Pós-Graduação e Pesquisa de Engenharia - Tese) - Universidade Federal do Rio de Janeiro, 2013.

[16] ASSOCIAÇÃO BRASILEIRA DE NORMAS TÉCNICAS - ABNT. NBR 10.004: Classificação dos Resíduos Sólidos. Associação Brasileira de Normas Técnicas, Rio de Janeiro, 2004.

[17] AGÊNCIA NACIONAL DE PETRÓLEO GÁS NATURAL E BIOCOMBUSTÍVEIS - ANP. Oficina Técnica: Logística Reversa dos Lubrificantes. Curitiba, 2013. Disponível em: http://www.anp.gov.br. Acesso em 26/11/2015.
[18] SINDICATO NACIONAL DA INDÚSTRIA DE RERREFINO DE ÓLEOS MINERAIS - SINDIRREFINO. Logística reversa de óleos lubrificantes e rerrefino. Rio de Janeiro, 2014.

[19] EUROPEAN COMISSION - EC. Integrated pollution prevention and control. Reference document on Best Available Techniques of the Waste Treatments Industries, 2006.

[20] AUDIBERT, F. Waste engine olis: Rerrefining and energy recovery. Oxford, Elservier, 2006.

[21] MONIER, V.; LABOUZE, E. Critical Review of existing studies on Life Cycle Analysis of the Regeneration and Incineration of Waste Oils. European commission, DG-environmental, A2-Sustentable resource consumption and waste. Taylor Nelson Sofres and Bio Intelligence Service. ADAME, 2001.

[22] PETRICORENA, T. Análise técnica, mercadológica e de tendências da indústria brasileira de óleos lubrificantes. UFRJ, Rio de Janeiro, 2005.

[23] SILVA, R. J. ; BELATO, M. e LOPES, A. Cooprocessamento de Pneus usados e resíduos de Rerrefino de óleos lubrificantes usados em forno de Clinquer. XX Congresso Brasileiro de Engenharia Química. Florianópolis, 2014. 